\title{
De Freud a Deleuze: os descaminhos da resistência
}

\author{
Fernanda Canavêz ${ }^{1}$ \\ Regina Herzog \\ Universidade Federal do Rio de Janeiro, Rio de Janeiro-RJ, Brasil
}

\begin{abstract}
Resumo: Este trabalho pretende problematizar o lugar marginal que a resistência pode vir a ocupar no campo psicanalítico, tomada como o que deve ser superado para a pretensa boa continuidade do processo de análise. Ao contrário desta perspectiva, indagamos se a resistência não poderia ser entendida como um espaço de produção subjetiva que, como tal, deve ser positivada. Nesse sentido, objetiva-se lançar mão de noções do campo da filosofia percorrendo algumas considerações de Deleuze a respeito do tema, para reconhecer na resistência não apenas um movimento de mero revide, mas uma afirmação primeira que traz a possibilidade efetiva de criação.
\end{abstract}

Palavras-chave: resistência, psicanálise clínica, cultura.

\section{From Freud to Deleuze: the under-ways of resistance}

\begin{abstract}
This work intends to work the marginal place which resistance has occupied in the psychoanalytical field, taken as what should be overcome in favor of the good continuity of the analytical process. Counter pointing this perspective, we question if the resistance couldn't possible be understood as a space of subjective production which, as such, should be positivated by the psychoanalysis. In this way, we take up the reading Deleuze does about this subject, in order to recognize in the resistance not a movement of simply payback, but a prime affirmation that brings a real possibility of creation.
\end{abstract}

Keywords: resistance, psychoanalysis clinic, culture.

\section{De Freud a Deleuze: los descaminos de la resistencia}

Resumen: Este trabajo pretende problematizar el lugar secundario que la resistencia viene tomando en el campo de la psicoanálisis, comprendida como lo que debe ser superado para la pretendida buena continuidad del proceso analítico. Al revés, preguntamos si la resistencia podría ser comprendida como un espacio de producción subjetiva que, como tal, debe ser positivada por la psicoanálisis. De esta forma, hacemos uso de la lectura que hace Deleuze acerca de la materia para reconocer la resistencia no como un movimiento de mera revancha, pero una afirmación primera que trae la posibilidad efectiva de creación.

Palabras clave: resistencia, psicoanálisis clínica, cultura.

Muito se discute sobre supostas crises pelas quais a nossa sociedade estaria passando na contemporaneidade. Diversos autores já se ocuparam do tema, sob diferentes ângulos, dentre os quais é possível citar, para exemplificar, Bauman (1998), Lipovetsky (2004), Sennett (2000). Tais crises perpassam assuntos como a falência da autoridade, o uso do corpo tido como mortífero, a precariedade das relações humanas ou até mesmo uma dificuldade para engendrar vínculos afetivos, a violência exacerbada e a corrosão do caráter. Eis aí somente alguns dos indicadores elencados não raras vezes por alguns estudiosos com grande alarde e preocupação.

A psicanálise, assim como os demais saberes no âmbito das ciências humanas, não passa incólume por toda esta discussão. Questiona-se se estaríamos diante de novos arranjos sintomáticos, para os quais a concepção freudiana de sintoma já estaria ultrapassada e até mesmo se o dispositivo psicanalítico poderia oferecer algo de pertinente àquele que busca um analista. A estes questionamentos somam-se as críticas outrora

\footnotetext{
'Endereço para correspondência:

Fernanda Canavêz. Rua Visconde de Pirajá, 282/1202. Ipanema. CEP 22.410-000. Rio de Janeiro-RJ, Brasil.E-mail: fernandacanavez@gmail.com
}

dirigidas à psicanálise, tão antigas quanto o seu próprio surgimento. Porém, com respeito à atualidade, fala-se de uma crise irreversível do dispositivo psicanalítico, assunto inclusive amplamente difundido na mídia.

Inúmeras matérias veiculadas nos últimos anos tiveram o tema como pauta. A título de exemplo, mais recentemente, uma matéria da capa da revista Superinteressante (Guedes, 2008) questionava a eficácia de diferentes tipos de orientações psicoterápicas. Tendo por título a questão “Terapia funciona?”, para a qual o artigo traz uma resposta afirmativa, o texto exalta o autoconhecimento como um processo através do qual se conquistaria a felicidade. "Mas Freud talvez não tenha nada a ver com isso", evidencia o subtítulo, convidando o leitor a uma matéria calcada em pesquisas de neuroimagens e "postulados científicos", em oposição a uma suposta falta de fundamentação das terapias, dentre as quais a de orientação psicanalítica.

Além desta crítica externa à psicanálise, dentro do próprio campo psicanalítico forjam-se explicações quanto às resistências por parte dos sujeitos para falarem de si, estabelecerem uma demanda de análise ou até mesmo reconhecerem nos sintomas o indício de que algo não vai bem, ainda que estes possam produzir efeitos destrutivos. Uma das leituras que se costuma fazer desta situação remete a uma suposta fragilidade 
psíquica dos sujeitos, decorrente de um processo de constituição psíquica que deixou a desejar, como se estivéssemos diante de sujeitos deficitários. Desse modo, caberia ao psicanalista trabalhar para a superação das resistências, no intuito de que o sujeito se enquadre no modus operandi da psicanálise, com direito a divã, associação livre e todos os demais elementos que sempre forneceram estofo à prática psicanalítica.

No tocante à técnica psicanalítica, o conceito de resistência surge atrelado ao de transferência, cuja importância se traduz no motor da experiência analítica. Muito embora Freud tenha apontado a importância das resistências no caminho a ser trilhado rumo ao núcleo patogênico, estas figuram como o que deve ser trabalhado pela análise. Na atualidade, a necessidade de superação das resistências pode se fazer premente, na medida em que os sujeitos parecem resistir à possibilidade de tratamento pela palavra, em última instância, ao enquadramento clínico que obteve êxito com as histéricas dos tempos freudianos.

Em linhas gerais, a resistência ocupa o lugar do grande vilão a ser combatido pelo analista ao longo da experiência de análise. Ainda que possa ser considerada como uma pedra no sapato a entravar o pretenso curso livre do processo analítico, o movimento de questionar o dispositivo psicanalítico não deixa de se fazer presente neste processo, o que nos leva a pensar que talvez seja pouco proveitoso concebê-la simplesmente como obstáculo a ser vencido. Deleuze e Guatarri (1992) mostram que todo conceito deve remeter a problemas, residindo aí a sua potência. Ficar aprisionado na abstração do conceito ou nos impasses que este pode suscitar em nada contribui para pensarmos a clínica na atualidade.

Neste sentido, indagamos se a resistência, para além de obstáculo, não remeteria a uma produção deveras singular do sujeito que deve ser acolhida pelo psicanalista. Destarte, poderíamos dizer que a resistência em abrir mão dos sintomas estaria a serviço de resguardar um espaço particular de produção do sujeito, espaço este capaz de se opor às tentativas de homogeneização levadas a cabo pela cultura de nossa época (Canavêz de Magalhães, 2008). Nessa visada, resistência e sintoma poderiam ser tomados mesmo como sinonímicos, uma vez que o sintoma neurótico é uma produção singular empreendida pelo sujeito, através da qual este se insere na cultura. Sendo assim, visamos compreender a resistência não como o que se opõe propriamente a algo, sendo concebida exclusivamente pelo negativo, mas sim como afirmação do sujeito.

Para tal empreitada, vamos lançar mão da noção de resistência presente no pensamento de Gilles Deleuze, em especial da leitura que este faz a partir de Foucault. Antes de recorrer a estes filósofos com vistas a conferir positividade à figura da resistência, é mister circunscrever primeiramente este conceito no pensamento freudiano.

\section{A resistência em Freud}

Assim como diversos outros conceitos da trama freudiana, a resistência comporta diferentes acepções, estando presente desde os primórdios de sua elaboração teórico-clínica. Em um primeiro momento ela aparece no sentido clássico, indicando um movimento que visa impedir a revelação dos desejos inconscientes no desenrolar do processo de análise (Freud, 1893-1895/1974); foi a partir daí que Freud começou a pensar o fenômeno na clínica. Esta é a acepção mais frequente, ainda que não seja a única. Também ao psicanalista é atribuída uma resistência ao longo do tratamento (Freud, 1912/1976), e para fazer face a esta situação, Freud ressalta a importância da experiência de análise dos até então médicos que pretendiam se tornar psicanalistas.

Extrapolando o processo de análise, este termo foi empregado com relação ao próprio movimento psicanalítico, uma vez que a sociedade resistia aos "achados" de Freud (Freud, 1910/1970; 1925/1976). Resistência motivada pelas novidades que a psicanálise propunha no tocante ao tratamento das neuroses, sobretudo pelas críticas às medidas coercitivas levadas a cabo pela moral sexual civilizada, em última análise, pelas críticas dirigidas à regulação normativa da sexualidade (Freud, 1908/1976).

Nas três dimensões apontadas, a resistência é compreendida como um ponto cego - seja para o analisando, para o psicanalista ou para a sociedade, nebulosidade que só seria dissipada através do processo analítico. Dito de outro modo, apenas a psicanálise poderia conferir clareza ao inexplicado, àquilo que escapava à apreensão da sociedade, do analisando e até mesmo da própria psicanálise.

Retomando a primeira acepção, a resistência aparece no início da elaboração freudiana como o principal obstáculo para o dispositivo analítico. Tal dispositivo funcionaria como um ringue no qual analista e as resistências que perpassam o psiquismo do analisando travariam sua luta, dependendo o sucesso do tratamento do trabalho a ser realizado com tais resistências. Mas, cabe salientar, este modo de encarar a resistência não concorria para o seu mero rechaço, uma vez que ela ganha um lugar de importância no tocante à própria dinâmica psíquica. Com efeito, as resistências que concorriam para a manutenção dos sintomas muito diziam a respeito do funcionamento psíquico. Ora, se as histéricas resistiam à revelação daquilo que as fazia caírem doentes, era preciso apostar na importância destas resistências e, além disso, questionar se os sintomas não funcionariam como algo a ser preservado, a despeito do sofrimento que acarretavam. Desse modo, embora o analista precisasse tomar a superação das resistências como o fio norteador de sua prática, era necessário recuar para compreender porque eram tão necessárias para as pacientes.

De maneira análoga, os sintomas - que nos primórdios do método psicanalítico tinham sido tomados como corpos estranhos invasores de sujeitos vitimizados (Schneider, 1993) também passaram a ensinar muito a respeito do funcionamento psíquico. Freud (1908/1976) pôde observar que o sintoma neurótico nada mais era do que o indício do conflito entre os desejos sexuais inconscientes e a moral sexual da época moderna, a qual era interiorizada pelos sujeitos modernos. Em outros termos, o 
sintoma era produto de um sujeito que se via - ainda que de maneira inconsciente - entre a "cruz e a espada", entre a realização de seus desejos mais íntimos e a moralidade que o inseria na ordem social. Da vitimização à responsabilidade pelos sintomas, Freud conferiu voz ativa aos neuróticos anteriormente tomados como símbolo da desrazão, a qual tanto amedrontava o homem moderno na constante busca por progresso.

Retirado dos recônditos da desrazão e da degenerescência, o sintoma neurótico e a resistência que lhe era correlata ganharam a cena principal da experiência analítica. Fazendo jus à sua maneira de pensar, Freud compreendia o sintoma como uma formação de compromisso, expondo uma conciliação entre os desejos inconscientes e a censura que sobre estes recaía. Embora os ditames morais estejam representados na formação sintomática pela figura da censura, também se fazem presentes os desejos inconscientes como forma de resistência às exigências morais. Assim, o sintoma encarna mais um paradoxo freudiano cujas partes não são subsumidas: de modo concomitante, expressa conciliação com a moralidade e resistência à mesma.

É importante atentar para a diferença entre a resistência evidenciada pelos desejos inconscientes na formação sintomática e a que estamos tentando positivar. Ora, com relação à primeira acepção da resistência é possível depreender certa compatibilidade com a censura, como se estivesse permanentemente circunscrita à lógica conciliatória. Propomos extrapolar esta dimensão para conceber uma outra forma de resistência. Trata-se daquela que guardaria o caráter inadaptável e inapreensível que identificamos no movimento de recusa em abrir mão dos sintomas ou até mesmo de respeitar o enquadre que garantiria a suposta boa continuidade do processo analítico.

É possível identificar no pensamento freudiano um esboço desta última acepção conferida à resistência se associamos este conceito ao trabalho libertário da pulsão de morte. Não raras vezes a pulsão de morte é tomada como um personagem que inspira certo temor no âmbito da experiência analítica, devido ao viés de destruição que pode comportar, em oposição à atividade de ligação evocada enquanto trabalho de Eros (Freud, 1929/1974). Todavia, esta perspectiva não é a única a figurar entre os psicanalistas. Zaltzman (1993) cunha o termo pulsão anarquista referindo-se ao que nomeia como a parte mais "individualista" da pulsão de morte, a qual se coloca efetivamente como resistência frente à ameaça de perigo mortal.

Trata-se de uma concepção subversiva que a autora encontra no próprio texto freudiano: assim, em vez do perigo se colocar do lado da pulsão de morte, Tânatos se erige contra a ameaça de totalização colocada em marcha por Eros que objetiva unir partes cada vez maiores, movimento este que poderia chegar a dissipar as marcas singulares do sujeito. Trazendo à baila a dimensão conflitiva que se estabelece entre sujeito e civilização (Freud, 1929/1974), Zaltzman (1993) retoma o embate entre Eros e Tânatos para afirmar que "às vezes, a vitória de Eros se volta para a autoconservação da civilização, com risco de usura, às vezes, a pulsão de morte trabalha em prol do mais individual levante libertário contra as formas sociais" (p. 65).
Isto remete ao trabalho libertário da pulsão de morte erigido contra as tentativas de regulação imputadas pela moral civilizada. Acreditamos que esta disposição nos fornece os elementos necessários para afirmar a resistência em sua dimensão política (Gondar, 2003), a saber, como contraponto efetivo ao projeto de homogeneização que acabava por tamponar as marcas singulares dos sujeitos dos quais Freud se ocupara, permitindo-nos dizer que ela pode comportar um caráter eminentemente positivo.

Vale ainda lembrar que Freud não atribuiu uma resistência apenas à instância do eu, que se faz notar nas exigências da censura inerentes à formação de compromisso. As resistências associadas ao eu são aproximadas do princípio de prazer, uma vez que almejam impedir o prazer acarretado com a liberação do recalcado. Além desta concepção, a resistência aparece ainda atrelada ao isso e ao supereu. Esta primeira é relacionada à inércia pulsional e à compulsão à repetição, ao passo que aquela atribuída ao supereu se faz notar pela necessidade de punição (Freud, 1926/1976). A compulsão à repetição e a necessidade de punição apontam para o modo de funcionamento da pulsão de morte, indicando agora um para além do princípio de prazer. A aliança entre resistência e pulsão de morte aponta para o inconciliável, atestando que há uma dimensão inassimilável em jogo no processo analítico, irredutível às tentativas de adequação ao próprio enquadre proposto pelo método em questão.

A resistência expressa no trabalho libertário da pulsão de morte parece extrapolar aquela circunscrita ao jogo conciliatório da formação de compromisso. O próprio Deleuze se dedicou à discussão da suposição freudiana da existência de uma pulsão de morte. O filósofo problematiza este conceito, na medida em que privilegia a dificuldade inicial por parte de Freud de tornar tangível tal classe de pulsões. Esta dificuldade, conforme a leitura de Deleuze, seria decorrente do fato de Tânatos só se apresentar no pensamento freudiano de modo fusionado às pulsões de vida, mas jamais em estado puro, como pura negação, tal como ele opta por concebê-lo. Para a consecução deste propósito, Deleuze propõe o termo instinto de morte, como princípio transcendental (Deleuze, 1967/1983). Instinto de morte que funciona como resíduo do princípio do prazer, pois é irredutível a todo e qualquer princípio, a todo e qualquer compromisso, como quisemos demonstrar. Nas palavras de Deleuze: "O instinto de morte não entra num ciclo com Eros, não é de modo algum complementar ou antagonista deste e de maneira alguma simétrico a este, mas dá testemunho de uma síntese totalmente distinta" (Deleuze, 1968/1988, p. 188).

Neste ensaio continuaremos a empregar o termo pulsão de morte, por supor que a dimensão disjuntiva, de pura negação enfatizada por Deleuze, já se encontra no pensamento freudiano. É o que sustenta Garcia-Roza, ao afirmar que a concepção de um além do princípio de prazer traz a noção de um "princípio disjuntivo portador da negação pura" (Garcia-Roza, 2003, p. 106), o qual não se apresenta apenas sob a égide de Eros, implodindo qualquer expectativa de encerrar o psíquico em uma trama de representações. 
Em consonância com esta perspectiva acerca da pulsão de morte, propomos avançar na busca de elementos que balizem a compreensão da noção de resistência como afirmação do sujeito. Para tanto, vamos nos servir das idéias de Deleuze acerca da resistência, bem como da leitura que o mesmo faz do pensamento de Foucault.

\section{Sobre as forças da resistência}

Antes de passar à discussão das idéias de Deleuze, cabe fazer algumas marcações a respeito da opção por este caminho expositivo. Conforme esboçado anteriormente, a proposta é utilizar alguns apontamentos do pensamento de Deleuze como subsídio para sustentar uma positivação da resistência na experiência analítica. Estamos cientes de que tal estratégia exige cuidado para não aproximar de forma apressada e inconsequente tramas conceituais de campos diversos. Diante dessas diferenças, ao menos dois caminhos são possíveis: recuar e afirmar uma impossibilidade de fazer as teorias dialogarem ou assumir os riscos de extrapolar os limites que circunscrevem determinada teoria para apostar na criação do novo. É desta segunda tomada de posição que Deleuze se faz partidário, não sendo sem propósito o fato de ter se ocupado de domínios heterogêneos ao seu campo de partida, como a arte e a própria psicanálise. Além disso, mesmo ao tratar da filosofia, Deleuze identifica a criação ao fio norteador de seu pensamento: mais do que propor reflexões, cabe ao filósofo criar (Boutang, 1989).

É sabido que tanto Foucault quanto Deleuze problematizam a noção de "sujeito", comumente encontrada no discurso psicanalítico. Para o primeiro seria mais pertinente falar em termos de formas de subjetivação (Foucault, 1984/1998) enquanto para o segundo caberia, por exemplo, falar em individuações sem sujeito (Deleuze \& Guattari, 1980/1997), proposição subversiva no tocante a uma determinada concepção estruturalista de sujeito. Com efeito, as singularidades são encarnadas como elementos de multiplicidades na concepção destes filósofos. Para além de um sujeito estruturado, esboçado de antemão, cuja forma subjaz sob o véu das defesas a serem descortinadas pelo psicanalista, o que está em pauta para estes filósofos são termos processuais, multiplicidades em permanente devir, em processo constante de remodelamento. Nesse sentido, as visadas dos mesmos acerca do "sujeito" estariam mais próximas das formulações herdeiras da segunda tópica freudiana, ou seja, daquelas que extraem as devidas consequências do funcionamento dinâmico das diferentes instâncias psíquicas, as quais se diferenciam progressivamente. No presente artigo o termo sujeito será mantido, não como uma figura estanque e estruturada previamente, mas em permanente remodelamento.

A despeito das diferenças (ou até mesmo por causa destas), apostamos na utilização das idéias de Deleuze como um caminho fértil para o debate aqui proposto, de maneira semelhante àquela com a qual este filósofo se apropriava de conceitos de pensadores os mais diversos. Ao falar do pensamento filosófico, Deleuze referia-se à idéia de colagem, tomada de empréstimo do movimento dadaísta, de maneira a propiciar que conceitos fossem retirados de seus berços de origem com vistas a serem utilizados a serviço de seu pensamento, independentemente das relações travadas com os demais conceitos próprios de seus sistemas de origem (Machado, 1990). Segundo Deleuze, “a História da Filosofia deve desempenhar um papel bastante análogo ao da colagem numa pintura" (Deleuze, 1968/1988, p. 19) e é nesta colagem que apostamos para ir em busca de elementos do campo filosófico que lancem luz à positividade da resistência. Vale ressaltar que esta positividade pode ser depreendida do pensamento freudiano, ainda que alguns de seus textos privilegiem outros aspectos da temática da resistência, conforme esboçado anteriormente.

Feita esta ressalva, vamos começar com algumas proposições de Deleuze a respeito do tema da resistência. De saída, cabe esclarecer que este assunto não se apresenta de maneira sistemática em seu pensamento. Todavia, certas passagens tangenciam a resistência, sendo interessante frisar que elas têm lugar algumas vezes por ocasião de críticas dirigidas à própria psicanálise, o que torna este debate ainda mais instigante.

Em Kafka: Por uma literatura menor, Deleuze e Guattari (1977) partem da literatura deste escritor para positivar o potencial de revolução em toda e qualquer literatura. Não se trata de estabelecer distinções entre uma literatura que seria mais abrangente e aquela que se destacaria como menor, mais particular. Ao contrário, o referido trabalho destaca-se por positivar o menor como a condição de revolução de toda literatura frente àquela estabelecida de antemão. Assim sendo, o caráter menor da literatura conservaria a possibilidade de resistir à imposição daquela previamente estabelecida, ou mesmo de reconhecer no seio da própria literatura tida como maior um potencial revolucionário.

Apesar de neste texto o tema da resistência ser apenas sinalizado, a propósito da potência de revolução, ainda assim os autores trazem à baila elementos importantes para o assunto no campo psicanalítico. Uma das características da literatura menor é a ênfase dada ao caráter político. Destarte, um caso individual não figura apenas como o diferente no seio de um contexto mais abrangente, de uma literatura maior. Trata-se de ligar cada caso individual à política. $\mathrm{O}$ "caso a caso" não estaria, portanto, a serviço de apontar traços individuais, os quais tomam "o meio social como ambiente e fundo" (Deleuze \& Guattari, 1977, p. 26), mas de constituir efetivamente um programa político.

De acordo com essa leitura, a tentativa de entender o sujeito a partir da compreensão superficial de seu drama familiar, edípico, seria de saída fracassada. Deleuze e Guattari (1976/1972) questionam a universalidade do complexo de Édipo e, por conseguinte, a concepção de desejo associada à castração. O que está em pauta é uma crítica contundente ao desejo engessado na dimensão de falta, ao contrário do caráter produtivo que os autores buscam enaltecer no desejo. Do mesmo modo, verificase também a implosão da noção psicanalítica mais corriqueira de sujeito, sempre remetida à falta, que cede lugar ao caráter 
coletivo do enunciado, pois segundo os autores só é pertinente falar em termos de agenciamentos coletivos de enunciação.

Um dos projetos subjacentes a esta argumentação é a crítica à filosofia da representação. Cai por terra a noção de que um enunciado remeteria a um sujeito de enunciação, este funcionando como causa daquele. De maneira análoga, encontra-se em xeque um modo de fazer psicanálise, engessado no dispositivo da interpretação e, por extensão, à linguagem tida como maior, assim como a literatura tomada como ordem pré-estabelecida. Por este motivo Deleuze e Guattari (1977) criticam o projeto psicanalítico de se colocar do lado da linguagem tomada como maior; e sugerem que seja utilizada de modo mais intensivo ou menor de seu fazer. Ou seja, eles se opõem a certa abordagem da psicanálise "que quer ser amante do significante, da metáfora e do jogo de palavras" (Deleuze \& Guattari, 1977, p. 42).

Em outras palavras, tal sugestão enaltece a criação, o saber "tornar-se menor", implicando a acepção de resistência que tomamos como política. E isto à medida que ressalta o potencial da linguagem de resistir à ordem pré-estabelecida e, de maneira análoga, do fazer psicanalítico de acolher as produções do sujeito que extrapolam os dispositivos pré-estabelecidos. Nesse sentido, a resistência também poderia ser concebida como apelo ao novo ou mesmo como possibilidade de questionar o enquadre psicanalítico ou o próprio modelo de sujeito cujo funcionamento psíquico está calcado exclusivamente no mecanismo do recalque.

Seguindo esta argumentação, no âmbito do dispositivo clínico, caberia então ao analista não uma postura receosa frente ao que possa colocar em xeque seu arcabouço teórico clínico, mas estar disponível para o encontro com esta forma de subjetivação. A recusa ao encontro com esta produção por parte do sujeito impediria que o psicanalista entrasse em contato com o que tenta escapar à adequação, diferenciando o sujeito dos demais, e não pressupõe, a princípio, compromisso. Dessa maneira, reside também neste encontro a especificidade do processo analítico como em permanente construção, calcado no vínculo transferencial, que permite à psicanálise prescindir de quaisquer dispositivos prescritivos de normalização estabelecidos aprioristicamente.

Nesta perspectiva, não seria o caso de positivar a força evidenciada pela resistência como um trilhar do sujeito rumo ao seu grito de alforria? A partir desta questão, retomemos a perspectiva da resistência como força que conserva sempre um caráter ativo. O pensamento de Foucault traz a concepção das forças não como meras respostas passivas ante as forças que afetam, na medida em que a força afetada não perde a sua capacidade de resistir ativamente. Cada força expressa de maneira concomitante o poder de afetar e de ser afetada, motivo pelo qual Deleuze (1986/2006) propõe que só seria pertinente pensar em forças no plural. Desse modo, a resistência que se erige contra o dispositivo analítico não perderia a sua capacidade de afetar, lhe sendo sempre reservado o potencial de resistir, de forma que a tentativa de subsumir tais forças seria caduca.
Ao tratar das especificidades da experiência analítica, Freud adverte para o fato de que "todo conflito deve ser combatido na esfera da transferência" (Freud, 1912/1976, p. 139). Portanto, ainda que a transferência possa estar a serviço das forças da resistência, é importante fazer compromissos com as mesmas, pois é só com este pano de fundo que uma análise pode se desenrolar. Com isso Freud subverte a concepção inicial de tratamento, segundo a qual as resistências deveriam ser superadas para se chegar ao núcleo das neuroses (Freud, 18931895/1974). Ao contrário, é preciso contemplá-las, uma vez que muito dizem a respeito do sujeito em questão.

Deleuze, por sua vez, ao discutir as relações de poder, assevera que a força "dispõe de um potencial em relação ao diagrama no qual está presa" (Deleuze, 1986/2006), potencial este que se apresenta como capacidade de resistência. Para extrair as devidas consequências desta assertiva é preciso circunscrever a noção de diagrama. Esta é pensada por Deleuze a partir da conceituação empreendida por Foucault (1975/2009) no tocante à sociedade disciplinar. Em linhas gerais, o diagrama é o mapa das relações de forças que constituem o poder, ou seja, trata-se de uma cartografia de "funções e matérias informes" (Deleuze, 1986/2006, p. 44) que, como tal, não tem uma definição previamente estabelecida.

Quando se fala em diagrama de forças, é importante esclarecer que estas não são estáticas, engessadas no diagrama do qual fazem parte. A título de esclarecimento, Deleuze enfatiza a distância deste conceito de uma idéia transcendente, apresentando-o como causa imanente, a saber, "aquela cujo efeito a atualiza, integra e diferencia" (Deleuze, 1986/2006, p. 46). Desse modo, não é possível estabelecer uma determinação entre causa e efeito, de modo que as relações de forças do diagrama só operam na virtualidade. Em outras palavras, é só através do seu efeito que o diagrama se atualiza.

Então, para Deleuze (1986/2006), se as relações de forças, quer dizer, as relações de poder, operam na virtualidade, são as relações de saber que as atualizam. Há, portanto, uma pressuposição recíproca entre poder e saber. As categorias de poder, ou seja, aquelas relativas à relação entre forças, de uma ação sobre outra ação, como suscitar e limitar ou normalizar, no caso da sociedade disciplinar, são atualizadas pelas categorias formais de saber, como punir e tratar. Portanto, os diagramas são puro devir, próprios de cada sociedade, de cada formação histórica, a depender das relações de forças que estas exprimem.

Deleuze afirma que o diagrama "nunca age para representar um mundo preexistente, ele produz um novo tipo de realidade, um novo modelo de verdade" (1986/2006, p. 45). Mas como escapar às relações de forças delimitadas por um dado diagrama? Como articular a produção deste novo tipo de realidade com a capacidade de resistência da qual dispõe a força mencionada anteriormente? Ora, embora o diagrama encerre determinadas relações de forças, estas estão em relação direta com o lado de fora, de onde os diagramas vieram. Deleuze propõe que as relações de poder se conservam no diagrama, ao passo que as forças de resistência evidenciam esta relação direta com o lado de fora (Deleuze, 1986/2006). 
Para melhor compreender esta visada acerca da resistência, cabe percorrer as três dimensões analisadas pelo filósofo, quais sejam, as relações formalizadas de saber, as relações de força do diagrama, isto é, as relações de poder e, por fim, a relação de tais forças com o lado de fora. Já vimos a ideia de pressuposição recíproca que explica a relação entre saber e poder, agora é importante nos deter sobre a concepção do lado de fora. Um diagrama está em relação com as formações estratificadas que o estabilizam, ou, melhor dizendo, com as categorias formais de saber que o atualizam. Está também em relação com outros diagramas, com outras forças instáveis que trazem, desse modo, a possibilidade de mutações.

No que diz respeito ao tema do presente artigo, estas considerações são preciosas, à medida que fundamentam o solo no qual é possível pensar o conceito de dobra, corrente no pensamento deleuziano. Falamos até o momento sobre o lado de fora, mas como pensar um lado de dentro, diferente da suposição de uma pretensa interioridade estanque, como queríamos demonstrar ao falar do modo como o sujeito seria tomado nesta argumentação? Deleuze desatrela o lado de fora de toda fixidez; ao contrário, o lado de fora é "uma matéria móvel, animada de movimentos peristálticos, de pregas e dobras que constituem um lado de dentro: nada além do lado de fora, mas exatamente o lado de dentro do lado de fora" (Deleuze, 1986/2006, p. 104).

Trata-se de uma espécie de interiorização do lado de fora, de modo que as relações aí situadas se dobram para fazer emergir uma relação consigo. A dobra é capaz de explicar tanto a produção de uma subjetividade, enquanto território que demarca uma determinada existência, quanto os próprios processos de subjetivação, através dos quais estes territórios são delineados. A dobra conjuga assim um lado de dentro que é coextensivo ao lado de fora, "sujeito" coextensivo ao social. Desse modo, a dobra não pode ser tomada como um processo concluído, mas em permanente construção, permanente atualização de relações com o lado de fora e, consequentemente, de relações consigo.

A partir deste campo de análise, é possível conceber uma subjetividade que, muito embora derive do poder e do saber, não é dependente destes. O "sujeito" é sempre uma derivada, "ele está por se fazer, como um foco de resistência, segundo a orientação das dobras que subjetivam o saber e recurvam o poder" (Deleuze, 1986/2006, p. 113). Nesse sentido, é possível até supor que a subjetivação se dá por intermédio da resistência, resistência que cria um dentro que é coextensivo ao fora.

Munidos destas considerações acerca da resistência no pensamento de Deleuze, é possível retomar uma acepção de resistência, agora circunscrita ao campo psicanalítico, fazendo frente ao dispositivo da clínica e, em última instância, ao saber da psicanálise. O próprio Deleuze (1986/2006) salienta a luta por uma subjetividade moderna nos termos de uma luta contra formas de sujeição: seja aquela relativa à exigência de individualização nos moldes do poder, ou ainda aquela que engessa o sujeito em uma identidade pré-concebida, a partir da qual qualquer resistência pode ser aventada como entrave a este modelo pré-moldado.
Por mais que os psicanalistas tentem interpretar a resistência para ultrapassá-la, esta estará sempre recolocando a capacidade de trazer o novo, de colocar em xeque o pré-estabelecido, de engendrar novas formas de relações consigo Essa força pode ser compreendida como mero indício da recalcitrância neurótica ou como incessante apelo à criação, à novidade, a não ser compatível com qualquer dispositivo que almeje limitar, disciplinar, conter.

\section{Por uma positivação da resistência na clínica psicanalítica}

Demonstramos a partir dos textos freudianos que, ainda que a resistência faça parte do processo analítico, o psicanalista se vê às voltas para trabalhar com esta força, correndo o risco de permanecer engessado nas tentativas de superação da mesma. Ainda que Freud tenha se dedicado a explicitar a importância da resistência, esta não perdeu a dimensão de mal para o qual o psicanalista deveria estar sempre alerta, tal qual Cérbero, o cão da mitologia grega que tinha por função guardar o Reino dos Mortos.

De maneira análoga, Cérbero recebeu a incumbência de impedir a saída das almas que entravam no Reino dos Mortos, assim como deveria se opor aos mortais que por lá se aventurassem. Ao considerar a resistência ameaçadora, também o psicanalista se coloca como guardião de uma pretensa boa continuidade do processo analítico, erigindo tentativas de entravar as produções do sujeito que se opõem ao enquadre pré-estabelecido. No entanto, assim como os mortais que se autorizavam a seguir por caminhos proibidos pelo Reino dos Mortos, o psicanalista não sai ileso da empreitada de se deparar com as formações do inconsciente. Freud já usara a metáfora do encontro com demônios para o laço transferencial por ocasião das dificuldades enfrentadas no caso Dora (Freud, 1905/1972).

$\mathrm{Na}$ verdade, ao tentar rechaçar a resistência, agora entendida como afirmação primeira do sujeito, o psicanalista acaba por se distanciar desta produção subjetiva que está a serviço de resguardar um espaço marcadamente peculiar do sujeito, singularizando-o.

Nesta perspectiva a resistência adquire um sentido político, advogando a favor do que se coloca frente a projetos totalizantes, isto é, às injunções que aspiram à universalidade (Gondar, 2003) e, com isso, chegam a subsumir as singularidades. Sugerimos que faz parte do fazer analítico acolher esta resistência, posto que demarca um espaço próprio ao sujeito. Em última instância, tal produção subjetiva comporta em si a possibilidade de preparar mutações, como atenta Deleuze, de modo que é cabível indagar se este não seria inclusive o próprio cerne da experiência analítica.

Com relação a este aspecto, cabe ainda tecer um último comentário. Ao longo de nossa exposição, estivemos afirmando a resistência como possibilidade criativa a ser positivada pela psicanálise. Vale apenas esclarecer que muito embora nosso esforço seja no sentido de extrapolar a compreensão da 
resistência pelo negativo, não é nosso objetivo tomá-la como um bem. Ao contrário, suspeitamos que o entendimento da resistência apenas como um bem a ser preservado a qualquer custo seria apenas o outro lado da moeda de pensá-la como produção ameaçadora a ser rechaçada. Nas duas faces teríamos diferentes maneiras de neutralizar o potencial das forças implicadas no fenômeno da resistência: seja pelo rechaço ou pelo enaltecimento.

Assim sendo, faz-se premente questionar se não estaríamos então recuando diante do inconciliável que o sujeito apresenta, concorrendo para que a psicanálise esteja à procura de sujeitos estandardizados, que caiam como uma luva no método sugerido por Freud para os sujeitos de sua época. Operando desse modo, a psicanálise funcionaria como mais um dispositivo, com a função estratégica de homogeneizar e categorizar as produções subjetivas (Chaves, 1988). Seguramente, obter popularidade não está entre os anseios da prática psicanalítica, como o próprio Freud (1922/1982) chamara atenção, apesar de determinada forma de difusão da psicanálise sinalizar o contrário, então em nome de quê os analistas poderiam abrir mão daquilo que há de mais particular nos sujeitos?

Com efeito, não temos fôlego para dar conta de todos os questionamentos e desdobramentos suscitados pelo artigo, mas consideramos que as contribuições filosóficas acerca das forças de resistência evidenciam sua fertilidade para impasses experimentados no campo psicanalítico. E isto na medida em que possamos tomar a resistência como afirmação primeira, ou seja, como aquilo que fala a favor da singularidade. Vimos que a resistência em abrir mão dos sintomas ou até mesmo que acaba aparecendo como oposição ao enquadre analítico erige-se a serviço de resguardar um espaço particular do sujeito que se atualiza como inconciliável. Por mais ameaçador e desconfortável que possa soar, cabe ao psicanalista apostar no sujeito, acolhendo essas forças inconciliáveis.

\section{Referências}

Bauman, Z. (1998). O mal-estar na pós-modernidade (M. Gama, Trad). Rio de Janeiro: Jorge Zahar. (Original publicado em 1997)

Boutang, P. (Diretor). (1989). L'abécédaire de Gilles Deleuze [DVD]. Paris: Éditions Montparnasse.

Canavêz de Magalhães, F. (2008). Compromisso e resistência: Considerações sobre o sintoma neurótico. Dissertação de mestrado não publicada, Universidade Federal do Rio de Janeiro, Rio de Janeiro.

Chaves, E. (1988). Foucault e a psicanálise. Rio de Janeiro: Forense Universitária.

Deleuze, G. (1983). Apresentação de Sacher-Masoch (J. Bastos, Trad.). Rio de Janeiro: Taurus. (Original publicado em 1967)

Deleuze, G. (1988). Diferença e repetição (L. Orlandi \& R. Machado, Trads.). Rio de Janeiro: Graal. (Original publicado em 1968)
Deleuze, G. (2006). Foucault (C. S. Martins, Trad.). São Paulo: Brasiliense. (Original publicado em 1986)

Deleuze, G., \& Guattari, F. (1976). O anti-édipo (G. Lamazière, Trad.). São Paulo: Imago. (Original publicado em 1972)

Deleuze, G., \& Guattari, F. (1977). Kakfa: Por uma literatura menor (J. C. Guimarães, Trad.). Rio de Janeiro: Imago.

Deleuze, G., \& Guattari, F. (1992). O que é a filosofia (B. P. Junior \& A. A. Muñoz, Trads.). São Paulo: Editora 34.

Deleuze, G., \& Guattari, F. (1997). Mil platôs: Capitalismo e esquizofrenia (S. Rolnik, Trad., Vol. 4). São Paulo: Editora 34. (Original publicado em 1980)

Foucault, M. (2009). Vigiar e punir: História da violência nas prisões (R. Ramalhete, Trad.). Petrópolis, RJ: Vozes. (Original publicado em 1975)

Foucault, M. (1998). História da sexualidade II: O uso dos prazeres (M. T. Costa Albuquerque, Trad.). Rio de Janeiro: Graal. (Original publicado em 1984)

Freud, S. (1974). Estudos sobre a histeria (C. M. Oiticica, Trad.). In J. Salomão (Org.), S. Freud, Edição standard brasileira das obras psicológicas completas de Sigmund Freud (Vol. 2). Rio de Janeiro: Imago. (Original publicado em 1983-1895)

Freud, S. (1972). Fragmento de análise de um caso de histeria (C. M. Oiticica, Trad.). In J. Salomão (Org.), S. Freud, Edição standard brasileira das obras psicológicas completas de Sigmund Freud (Vol. 7, pp. 1-119). Rio de Janeiro: Imago. (Original publicado em 1905)

Freud, S. (1976). Moral sexual 'civilizada' e doença nervosa moderna (M. A. M. Rego, Trad.). In J. Salomão (Org.), S. Freud, Edição standard brasileira das obras psicológicas completas de Sigmund Freud (Vol. 9, pp. 185-208). Rio de Janeiro: Imago. (Original publicado em 1908)

Freud, S. (1970). As perspectivas futuras da terapêutica psicanalítica (D. Mussa, Trad.). In J. Salomão (Org.), S. Freud, Edição standard brasileira das obras psicológicas completas de Sigmund Freud (Vol. 11, pp. 125-136). Rio de Janeiro: Imago. (Original publicado em 1910)

Freud, S. (1976). A dinâmica da transferência (J. O. A. Abreu, Trad.). In J. Salomão (Org.), S. Freud, Edição standard brasileira das obras psicológicas completas de Sigmund Freud (Vol. 12, pp. 131-143). Rio de Janeiro: Imago. (Original publicado em 1912)

Freud, S. (1976). As resistências à psicanálise (J. O. A. Abreu, Trad.). In J. Salomão (Org.), S. Freud, Edição standard brasileira das obras psicológicas completas de Sigmund Freud (Vol. 19, pp. 263-279). Rio de Janeiro: Imago. (Original publicado em 1925)

Freud, S. (1976). Inibições, sintomas e ansiedade (C. M. Oiticica, Trad.). In J. Salomão (Org.), S. Freud, Edição standard brasileira das obras psicológicas completas de Sigmund Freud (Vol. 20, pp. 95-201). Rio de Janeiro: Imago. (Original publicado em 1926) 
Freud, S. (1974). O mal-estar na civilização (J. O. A. Abreu, Trad.). In J. Salomão (Org.), S. Freud, Edição standard brasileira das obras psicológicas completas de Sigmund Freud (Vol. 21, pp. 75-171). Rio de Janeiro: Imago. (Original publicado em 1929)

Freud, S. (1922/1982). Carta de 14 de maio de 1922 (A. S. Santos, Trad.) In S. Freud, Correspondência de amor $e$ outras cartas: 1873-1939 (pp. 396-397). Rio de Janeiro: Nova Fronteira.

Garcia-Roza, L. A. (2003). Acaso e repetição em psicanálise: Uma introdução à teoria das pulsões (7a ed). Rio de Janeiro: Jorge Zahar.

Gondar, J. (2003). A sociedade de controle e as novas formas de sofrimento. In M. Arán (Org.), Soberanias (pp. 81-89). Rio de Janeiro: Contra Capa.

Guedes, D. (2008, julho). Terapia funciona? Revista SuperInteressante, 60-69.

Lipovetsky, G. (2004). Os tempos hipermodernos (M. Vilela, Trad.). São Paulo: Barcarolla.

Machado, R. (1990). Deleuze e a filosofia. Rio de Janeiro: Graal.

Schneider, M. (1993). Afeto e linguagem nos primeiros escritos de Freud (M. M. Seincman, Trad). São Paulo: Escuta.

Sennet, R. (2000). A corrosão do caráter: As consequências pessoais do trabalho no novo capitalismo (M. Santarrita, Trad.). Rio de Janeiro: Record. (Original publicado em 1998)

Zaltzman, N. (1993). A pulsão anarquista (A. C. R. Aguilar, Trad.). São Paulo: Escuta.

Fernanda Canavêz é doutoranda em Teoria Psicanalítica pelo Programa de Pós-graduação em Teoria Psicanalítica do Instituto de Psicologia da Universidade Federal do Rio de Janeiro, bolsista CAPES.

Regina Herzog é Professora Associada do Programa de Pósgraduação em Teoria Psicanalítica do Instituto de Psicologia da Universidade Federal do Rio de Janeiro, campus da Praia Vermelha.

Recebido: $11 / 02 / 2009$

$1^{a}$ revisão: 20/09/2009

$2^{a}$ revisão: 20/04/2010

Aceite final: 13/05/2010 